\title{
Effectiveness of Jacobson's Progressive Muscle Relaxation Technique in Reduction of Stress among Postmenopausal Women in Selected Hospital
}

\author{
B. Batra, Dolly John Shiju \\ Department of Obstetrics and Gynaecological Nursing, R K D F College of Nursing, Sarvepalli Radhakrishnan University, Bhopal, Madhya Pradesh, India
}

\section{Abstract}

Aim: The aim of the study is to assess the effectiveness of Jacobson's progressive muscle relaxation technique (MRT) among postmenopausal women in selected hospital.

Materials and Methods: Pre-experimental one group pre-test and post-test method was adopted for the study. 60 postmenopausal were selected by convenient sampling technique. Pre- and post-test assessment was done using Dr. M. Singh Stress Scale Assessment Scale.

Results: The stress level of postmenopausal women was decreased after administration of Jacobson's progressive MRT.

Conclusion: Jacobson's progressive MRT is an effective way in reducing stress among postmenopausal women.

Keywords: Jacobson's progressive muscle relaxation technique, postmenopausal women, stress reduction

\section{INTRODUCTION}

Menopause is not considered a disease or a condition. It is a normal part of the life of every woman when they enter their fifth decade of life. ${ }^{[1]}$ The menstrual irregularity may persist for 4 years in $90 \%$ of women who are attaining their menopause. ${ }^{[2]}$ During menopausal period, women experience both physiological and psychological changes. ${ }^{[3]}$ Physiological changes include hot flushes, joint pain, irritable bowel movements, weight gain, and hair loss. Psychological changes include anxiety, depression, and stress. Women experience stresses in many ways and can be external and internal. It can cause changes in body images, attitude toward aging, and also leads to mood changes. Yoga, meditation, progressive muscle relaxation, and physical exercises are the methods used to

\section{Access this article online}

Website: http://innovationalpublishers.com/Journal/ijnmi

ISSN No: $2656-4656$

DOI: $10.31690 / \mathrm{ijnmi} / 41$ reduce menopausal stress. Physical exercise can also help to maintain health. Stress associated with menopause can also be reduced by practicing Benson relaxation technique. According to Women Health Organization, all the women should practice yoga and other relaxation techniques to maintain health and to reduce stress. ${ }^{[4]}$ In a survey conducted in India, 75\% of women experience anxiety during menopausal period. In the survey, it reports that natural menopause may occur at 45-55 years in $83 \%$ of women. Late menopause occurs after the age of 55 in $5 \%$ of women. Early menopause between 40 and 45 years occurs in $5 \%$ of women. In a survey conducted in India, $77 \%$ of postmenopausal women under stress say anxiety or disorders such as insomnia or depression hamper their marital relationships. It also reports that the incidence of early and natural menopause is increasing than surgical menopause. ${ }^{[5]}$ Edmond Jacobson (1929) first caught on to this idea of tension and relaxation in muscles. He found that the patients were able to diminish the severity of muscle tension by relaxation. It is also known as Progressive Relaxation Therapy. The stress is a tension. Relaxation is a state opposite to stress. The body's natural relaxation response is a powerful antidote to stress.

Address for Correspondence:

Dolly John Shiju, Department of Obstetrics and Gynaecological Nursing, R K D F College of Nursing, Sarvepalli Radhakrishnan University, Bhopal, Madhya Pradesh, India. E-mail: dollyshiju@gmail.com

This is an open-access journal, and articles are distributed under the terms of the Creative Commons Attribution Noncommercial Share Alike 4.0 License, which allows others to remix, tweak, and build upon the work non-commercially, as long as appropriate credit is given and the new creations are licensed under the identical terms 
Jacobson's progressive muscle relaxation technique (MRT), when practiced regularly, leads to a reduction in everyday stress level and a boost in feelings of joy and serenity. In progressive MRT, first, deliberately apply tension to certain muscle groups and then let it go. Thus, there are two steps in progressive muscle relaxation procedure.

\section{Objectives}

The study sought to (1) assess the pre-test level of stress among postmenopausal women before imparting Jacobson's progressive MRT, (2) impart the Jacobson's progressive MRT among menopausal women, (3) assess the effectiveness of Jacobson's progressive MRT in relation of the reduction of stress among postmenopausal women after imparting Jacobson's progressive MRT, and (4) find out association between the pretest score of stress and selected sociodemographic variables of postmenopausal women.

\section{Materials And methods}

An evaluative approach using pre-experimental one group pre-test and post-test was used. The present study was carried out in Sultania Zanana Hospital at Bhopal (M.P.). The protocol and informed consent process of the study has been submitted to the Institutional Ethics Committee (IEC). After getting approval from the IEC, the study was started in the department of Obstetrics and Gynaecological in the hospital considered for the research. The study population included of 60 menopausal women selected through convenient sampling technique.

\section{Study tool}

The selection and development of tool consist of two sections:

- Section-A: Sociodemographic data.

- Section-B: Dr. M. Singh Stress Scale.

Section-A: Sociodemographic data: Demographic data which consist of 10 items for obtaining information about selected factors such as age, religion, educational status, marital status, monthly income, source of income, and area of residence

Section-B: Dr. M. Singh Stress Scale: This is a selfevaluation rating scale developed by Dr. M. Singh, in 2002. This standardized tool consists of 40 statements which show the signs of stress. Each statement has four choices, numbering which is indicated as $0=$ Never, $1=$ Sometimes, and $2=$ Most of the times, respectively, which the respondent has to mark to indicate how he is self-right at the moment of testing.

\section{Score interpretation}

Dr. M. Singh Stress Scale consisted of 40 statements. Each statement had three responses that are scored as 0,1 , and 2 (never, sometimes, and most of the times). Score on each item refers to the level of stress of menopausal women. The score was interrupted as follows: (1) Low level of stress, 0-15 (scores), (2) moderate level of stress, 16-25 (scores), (3) high level of stress, 26-40 (scores).

\section{Data collection procedure}

Postmenopausal women were informed regarding the research study and written consent obtained initially. The investigator assessed the level of stress using Dr. M. Singh Stress Scale. It took 10-15 min for the assessment with each participant. After that, Jacobson's progressive MRT was demonstrated to them. Then, they were asked to do return demonstration and given practice regularly for $30 \mathrm{~min}$ before breakfast every day for a week. On the $8^{\text {th }}$ day, post-test was conducted using Dr. M. Singh Stress Scale.

\section{Plan for data analysis}

The data were analyzed in terms of the objective of the study using both descriptive and inferential statistics. The plan for data analysis will be as follows: (1) Organizing data in a master sheet, (2) frequency and percentage distribution of demographic characteristics of the samples, (3) Chi-square test to establish association between stress and selected demographic variables, and (4) paired $t$-test to assess the effectiveness of Jacobson's progressive MRT.

\section{RESULTS}

The data collected were organized and presented under the following sections. Section-I: Description of sociodemographic variables of postmenopausal women with stress [Tables 1 and 2]. Section-II: Distribution of postmenopausal women according to the scores of stress. Section-III: Analysis of the effectiveness of Jacobson's

Table 1: Frequency and percentage distribution of postmenopausal women

\begin{tabular}{lc}
\hline Demographic variables & Frequency (f) (\%) \\
\hline Age & $14(23)$ \\
45-50 years & $09(16)$ \\
$51-55$ years & $14(23)$ \\
$56-60$ years & $23(38)$ \\
61 years and above & \\
Religion & $48(80)$ \\
Hindu & $03(05)$ \\
Muslim & $09(15)$ \\
Christian & $00(00)$ \\
Any other & \\
Education & $17(28.3)$ \\
Illiterate & $34(56.6)$ \\
Primary & $05(08.3)$ \\
Secondary & $04(06.8)$ \\
Graduation and above & \\
Marital status & $40(66.7)$ \\
Married & $30(21.7)$ \\
Divorced & $02(03.3)$ \\
Widow & $05(08.3)$ \\
Unmarried & \\
Monthly income & $00(00)$ \\
$>5000 /-$ & $20(33.4)$ \\
5001/--9000/- & $30(50)$ \\
9001/--10,000/- & $10(16)$ \\
$<10,000 /-$ & \\
Area of residence & $09(15)$ \\
Urban & $51(85)$ \\
Rural &
\end{tabular}


Table 2: Distribution of postmenopausal women according to the scores of stress

\begin{tabular}{lccc}
\hline Level of stress & Pre-test & & Post-test \\
\cline { 2 - 2 } & Frequency (\%) & & Frequency (\%) \\
\hline Low level of stress & $10(16.7)$ & & $28(46.7)$ \\
Moderate level of stress & $45(75)$ & & $32(53.3)$ \\
High level of stress & $5(8.3)$ & & - \\
Total & $60(100)$ & & $60(100)$ \\
\hline
\end{tabular}

progressive MRT in reduction of stress among menopausal women. Section-IV: Association between the sociodemographic variables and stress level among the menopausal women.

\section{Discussion}

Menopause is a natural process when women experience physiological changes that may interfere with their ability to cope with their new psychological and social status and affect their quality of life. ${ }^{[5]}$ The study found that $75 \%$ of the postmenopausal women had moderate level of stress. $16.7 \%$ of postmenopausal women had low level of stress and $8.3 \% \%$ of postmenopausal women had high level of stress. The overall mean of post-test of the stress level is decreased from $29.02 \%$ to $19.62 \%$ after administering Jacobson's progressive MRT.

The association between stress levels of postmenopausal women was significant at $5 \%$ level to certain demographic variables that were age, education, and marital status. Jacobson's progressive muscle relaxation is a great technique for reducing body tension, as the tension reduce whole body will feel less stress. ${ }^{[6]}$ In addition, relaxation brings positive change in thinking and directing toward an open approach. Hence, this study is selected to help the postmenopausal women to reduce their anxiety with a simple relaxation technique without any side effects. ${ }^{[7]}$

\section{Conclusion}

Menopause is a universal and irreversible part of the overall aging process involving a women's reproductive system, after which she is no longer menstruate. Hormonal changes can produce feeling of stress in women of menopausal age. Women should have a clear knowledge about menopause and psychological as well as physical changes. Understanding these aspects of menopause can help women to determine the best way to manage and treat changes during menopause. Thus, the MRT finding of this study revealed that Jacobson's progressive MRT was an effective intervention in reducing the stress among postmenopausal women.

\section{RefEREnCES}

1. Nordaqvist C. Everything you need to know about menopause. Medical News Today MediLexicon Intl; 28 September, 2017. Available from: https://www.medicalnewstoday.com/articles/155651.php. [Last accessed on 2019 Feb 22].

2. Mary V. Essentials of Obstetric and Gynaecology Nursing. $3^{\text {rd }}$ ed. New Delhi, India: Elsevier Publishers; 2010. p. 451-3.

3. Tiwari SC, Pandey Nisha M. Status and requirements of geriatric mental health services in India: An evidence-based commentary. Indian J Obstet Gynaecol Nurs 2012;54:8-14.

4. Singh I. Mental health problems among inhabitants of old age homes: A preliminary study. Indian J Obstet Gynaecol Nurs 2012;54:144-5.

5. Fogoros RN. The benefits of progressive muscle relaxation. Stress Manage 2018;6:18-9.

6. Rapp MS. Thomas MR. Muscle Relaxation Technique in treatment of anxiety. Pender NJ. Effects of progressive muscle relaxation technique on anxiety. Res Nurs Health 2005;8:67-70.

7. Berry D. Evaluation of progressive muscle relaxation on stress related symptoms. J Clin Psychol 2007;10:342-6.

How to cite this article: Batra B, Shiju DJ. Effectiveness of Jacobson's Progressive Muscle Relaxation Technique in Reduction of Stress among Postmenopausal Women in Selected Hospital. Int J Nurs Med Invest. 2019;4(1):4-6. 